\title{
Pharmacogenomics: A Promising Approach Towards Treatment of Autism
} Hansen Wang*

Faculty of Medicine, University of Toronto, 1 King's College Circle, Toronto, Ontario, Canada, M5S 1A8

\begin{abstract}
Pharmacogenomics investigates variations in the human genome and the ways in which genetic diversity might influence individual response to drug treatment. Autism is a complex genetic disorder, which awaits a pharmacogenomic approach to better its treatment. This article describes recent developments of genetics and pharmacogenomics in the field of autism, and highlights the prospective of pharmacogenomics in developing novel and more effective therapies, and personalizing treatment strategies for autism.
\end{abstract}

\section{Introduction}

Autism spectrum disorders (ASDs) are among the most common neuropsychiatric disorders, with an estimated worldwide prevalence of $1 \%-2.6 \%$ [1-3]. The affected individuals display deficits in social communication, impaired language development, and the presence of highly restricted interests and/or stereotyped repetitive behaviours [1,2,4-6]. Although a wide variety of treatments have been used to treat individuals with ASD, no curative therapies are currently available. Treatment approaches to autism generally focus on educational and behavioural interventions. Drug therapies are mainly used to treat specific disruptive behaviours, such as anxiety, irritability, hyperactivity, inattention, obsessive-compulsive symptoms, sleep disturbances, aggression and self-injury, which are usually associated with autism and negatively affect the success of educational treatments and quality of family life [7-14].

Pharmacological treatment of ASDs is challenged by the complexities of the disorders in nature [9-11]. Obviously, the treatment is often complicated by the frequent presence of comorbid disorders, such as epilepsy, bipolar disorder, attention deficit-hyperactivity disorder, gastrointestinal and immune system disorders [12,13]. Usually, medications are used in combination to treat accompanying symptoms including anxiety, obsessions, hyperactivity, impulsivity, irritability and aggressive behaviours. The most frequently prescribed medications for patients with ASDs include antipsychotics, antidepressants, anticonvulsants, mood stabilizers, and cholinesterase inhibitors [7,8,10-13,15-17]. However, the efficacy of most of these medications among patients with ASDs has been uncertain. In fact, few placebocontrolled, double-blind studies have been performed on any of these medications. As a result, much of our current knowledge of treatment of ASDs has been from trials-and-errors regarding the selection of medications. Little attention has been paid to the atypical responses of individual patients to certain medications and the genetic background of these individuals $[10,11,14,18]$. Thus, a pharmacogenomic approach is definitely needed to better the treatment of ASDs.

\section{Genetic diversity of autism}

Genetic diversity, most notably through single nucleotide polymorphisms (SNPs) and copy-number variations (CNVs), together with specific environmental exposures, contributes to both disease susceptibility and drug response variability [19-21]. ASDs represent a heterogeneous group of disorders that are highly heritable, with heritability indices estimated at $85 \%-92 \%$ [3,22]. Advances in identifying the genetic causes of ASDs first came from the study of syndromic autism, which pinpointed the causes of disorders, such as fragile X syndrome, Rett syndrome, tuberous sclerosis, and Timothy syndrome [22-25]. However, the challenges were more from identifying the genetic causes of nonsyndromic or idiopathic autism given the lack of defining features besides the neurobehavioral phenotypes and the fact that the majority of cases were simplex. The genome-wide approaches that are capable of screening thousands of DNA mutations or structural variants at once have been applied to the studies of ASDs. Many significantly associated SNPs have been identified in these studies. Recent studies of simplex and mostly nonsyndromic ASDs, have established de novo copy number variants (CNVs) as the cause of $5 \%-8 \%$ of cases of simplex autism [26-28].

Generally, ASDs have been widely viewed as complex genetic disorders, with each gene having a minor effect on the overall clinical presentation $[19,20]$. With the development of genome-wide association (GWA) studies, more comprehensive approaches will become available and greatly accelerate genomics research in ASDs. The genome-wide study of ASDs will link more genotypes to their biological phenotypes, thus provides a foundation for the development of diagnostic screens as well as pharmacogenomic studies [29-33]. Furthermore, some of the genes associated with the identified SNPs or CNVs will offer new insight into the pathology of ASDs as well as novel therapeutic targets for treatment of ASDs [19-21,34,35].

\section{Development of pharmacogenomics in autism}

The goal of pharmacogenomics is to dissect the clinical variability between individuals with regard to drug therapy and to predict drug response and side effects based on genetic diversity [3640]. In comparison with other neuropsychiatric disorders, such as drug addiction, schizophrenia and depression [37-39,41-43], pharmacogenomic research in ASDs is still in its initial stage [18]

*Corresponding author: Hansen Wang, Faculty of Medicine, University of Toronto, 1 King's College Circle, Toronto, Ontario, M5S 1A8, Canada, E-mail: hansen.wang@utoronto.ca

Received January 19, 2012; Accepted January 20, 2012; Published January 23 2012

Citation: Wang H (2012) Pharmacogenomics: A Promising Approach Towards Treatment of Autism. J Pharmacogenom Pharmacoproteomics 3:e110. doi:10.4172/2153-0645.1000e110

Copyright: (c) 2012 Wang $\mathrm{H}$. This is an open-access article distributed under the terms of the Creative Commons Attribution License, which permits unrestricted use, distribution, and reproduction in any medium, provided the original author and source are credited. 
Challenges facing pharmacogenomics of ASDs are mainly from the lack of information about the biology of ASDs in addition to the welldocumented clinical heterogeneity within patients of ASDs [18,34].

In recent years, there have been a few encouraging studies of pharmacogenomics in ASDs. Antipsychotic medication is commonly used in children with ASDs, with risperidone one of the most popular atypical antipsychotics prescribed. Though risperidone significantly improves behavioural problems in most situations, it is also associated with mild adverse effects [44-46]. It is known that there are considerable individual differences in response to risperidone, both regarding therapeutic and adverse effects, which actually limit the therapeutic use of the drug [46-49]. Little has been reported on the genetic factors, which may underlie this individual variability in response to risperidone therapy, particularly for autism. Correia et al. [50] explored the effects of multiple candidate genes on clinical improvement and occurrence of adverse drug reactions in patients who received single therapy with risperidone up to 1 year. Candidate genes involved in the pharmacokinetics (CYP2D6 and ABCB1) and pharmacodynamics (HTR2A, HTR2C, DRD2, DRD3, HTR6) of the drug, and the brain-derived neurotrophic factor $(B D N F)$ gene, were analysed in this study. Their results confirmed that risperidone therapy is effective in reducing some autism symptoms and cause few serious adverse effects. They further found that the HTR2A c.-1438G >A, DRD3 Ser9Gly, HTR2C c.995G $>$ A and ABCB1 $1236 \mathrm{C}>\mathrm{T}$ polymorphisms are predictors for clinical improvement with risperidone therapy. The HTR2A c.-1438G>A, HTR2C c.68G>C (p.C33S), HTR6 c.7154$2542 \mathrm{C}>\mathrm{T}$ and $B D N F$ c.196G $>\mathrm{A}$ (p.V66M) polymorphisms influenced prolactin elevation. HTR2C c.68G $>\mathrm{C}$ and CYP2D6 polymorphisms were associated with risperidone-induced increase in body mass index (BMI) or waist circumference. This study thus identified for the first time several genes implicated in risperidone efficacy and safety in autism patients. It provides hope for the personalized therapy of risperidone in autism. Another study focused on escitalopram, a selective serotonin reuptake inhibitor (SSRI), which has been found to effective in the treatment of certain symptoms of patients with ASDs, including repetitive behaviours, anxiety, irritability, aggression and self-injurious behaviours [51-53]. Since variation in the gene that codes for the primary protein target of SSRIs, the serotonin transporter, could be related to escitalopram response or final dose of treatment [52], a complex insertion/deletion/single nucleotide containing polymorphism in the promoter region of the transporter (5-HTTLPR) was chosen as the primary candidate polymorphism [54]. Owley et al. [55] determined the effect of 5-HTTPLR genotypic variation (low, intermediate, and high expression groups) on the response to escitalopram treatment of children and adolescents with ASDs. They found that groups with different haplotypes affecting expression of the serotonin transporter may differ in their response to escitalopram. Given that the study was carried out in a small sample of patients, replication in a larger independent sample is definitely needed to confirm whether serotonin transporter genotype is related to response to escitalopram in ASDs. Interestingly, the next most recent study investigated whether peripheral blood gene expression before treatment with risperidone is associated with improvements in severe behavioral disturbances following risperidone treatment in ASD patients. Lit et al. [56] compared exon expression levels in blood before risperidone treatment with pre-post risperidone change in Aberrant Behavior Checklist-Irritability (ABC-I) scores. They found that expression of exons within five genes (GBP6, RABL5, RNF213, NFKBID and $R N F 40$ ) was correlated with change in ABC-I scores in all risperidonetreated patients. Of these five genes, RNF40 is located at 16p11.2, a chromosome region involved in autism and schizophrenia $[57,58]$. They concluded that the expression of these genes before treatment is associated with subsequent clinical response. This study is the first to suggest that gene expression in blood is associated with and may predict the behavioral response to risperidone use in ASDs. The gene expression profiles identified here may reflect convergent downstream biological mechanisms across multiple genetic backgrounds that are associated with behavioral response to risperidone in ASDs.

Although the above studies have made significant progresses towards pharmacogenomics of autism, none of their results could entirely account for the heterogeneity in response to autism treatment, and all of the results have to be replicated or validated in further studies. Undoubtedly, large-scale genetic and gene expression analysis will be performed in the near future in many laboratories by using the technologies of functional genomics. The expected findings will provide novel insights into the pathophysiology of ASDs. Such detailed knowledge will ultimately have profound effects on the treatment of these disorders.

\section{Prospective of pharmacogenomics in autism}

Addressing the extensive unmet medical needs related to autism will require that novel pharmacotherapies be developed [14,59]. Numerous molecular mechanisms that could potentially be targeted have been discovered by basic research in genetics and neurobiology of autism, but clinical translation remains a challenge. Developing therapeutics targeting these mechanisms will require the approach of pharmacogenomics.

The pharmacogenomic approach takes advantage of recent advances in experimental genomics and proteomics, together with the available information of the Human Genome Project [32]. It will not only enable genome-wide screens of several millions of SNPs without the specific hypotheses or candidate gene strategy, but also functional investigations of genetic diversity and gene expression over the whole genome or proteome $[32,33]$. We hope that an improved understanding of complexities of ASDs by pharmacogenomic approach will continuously contribute to the optimization of current therapies and the development of novel and potentially more powerful therapeutic strategies for these disorders. Furthermore, the determination and identification of patient subpopulations in response to drug treatment will help individualize pharmacological therapy for patients of autism.

\section{References}

1. Kim YS, Leventhal BL, Koh YJ, Fombonne E, Laska E, et al. (2011) Prevalence of autism spectrum disorders in a total population sample. Am J Psychiatry 168: 904-912.

2. Kogan MD, Blumberg SJ, Schieve LA, Boyle CA, Perrin JM (2009) Prevalence of parent-reported diagnosis of autism spectrum disorder among children in the US, 2007. Pediatrics 124: 1395-1403.

3. Schaaf CP, Zoghbi HY (2011) Solving the autism puzzle a few pieces at a time. Neuron 70: 806-808.

4. Aldridge K, George ID, Cole KK, Austin JR, Takahashi, et al. (2011) Facia phenotypes in subgroups of prepubertal boys with autism spectrum disorders are correlated with clinical phenotypes. Mol Autism 2: 15

5. Christ SE, Kester LE, Bodner KE, Miles JH (2011) Evidence for selective 
inhibitory impairment in individuals with autism spectrum disorder. Neuropsychology 25: 690-701.

6. Ingram DG, Takahashi TN, Miles JH (2008) Defining autism subgroups: a taxometric solution. J Autism Dev Disord 38: 950-960.

7. FDA (2007) First drug to treat irritability associated with autism. FDA Consum 41: 4.

8. The Harvard mental health (2009) Drug fails to subdue repetitive behavior in children with autism spectrum disorders. Harv Ment Health Lett 26: 7.

9. Hampson DR, Gholizadeh S, Pacey LK (2011) Pathways to Drug Development for Autism Spectrum Disorders. Clin Pharmacol Ther.

10. Malone RP, Gratz SS, Delaney MA, Hyman SB (2005) Advances in drug treatments for children and adolescents with autism and other pervasive developmental disorders. CNS Drugs 19: 923-934.

11. McCracken JT (2005) Safety issues with drug therapies for autism spectrum disorders. J Clin Psychiatry 10: 32-37.

12. Schaaf CP, Sabo A, Sakai Y, Crosby J, Muzny D, et al. (2011) Oligogenic heterozygosity in individuals with high-functioning autism spectrum disorders. Hum Mol Genet 20: 3366-3375.

13. Villagonzalo KA, Dodd S, Dean O, Gray K, Tonge B, et al. (2010) Oxidative pathways as a drug target for the treatment of autism. Expert Opin Ther Targets 14: $1301-1310$.

14. Stahmer AC, Schreibman L, Cunningham AB (2011) Toward a technology of treatment individualization for young children with autism spectrum disorders. Brain Res 1380: 229-239.

15. Danielsson S, Viggedal G, Gillberg C, Olsson I (2008) Lack of effects of vagus nerve stimulation on drug-resistant epilepsy in eight pediatric patients with autism spectrum disorders: a prospective 2-year follow-up study. Epilepsy Behav 12: 298-304.

16. Nobile M, Perego P, Piccinini L, Mani E, Rossi A, et al. (2011) Further evidence of complex motor dysfunction in drug naive children with autism using automatic motion analysis of gait. Autism 15: 263-283.

17. Tutkunkardas MD, Mukaddes NM (2010) Drug induced mania in a boy with high functioning autism. Psychopharmacol Bull 43: 82-85.

18. Hu VW (2011) A systems approach towards an understanding, diagnosis and personalized treatment of autism spectrum disorders. Pharmacogenomics 12: 1235-1238.

19. Eapen V (2011) Genetic basis of autism: is there a way forward? Curr Opin Psychiatry 24: 226-236

20. Geschwind DH (2011) Genetics of autism spectrum disorders. Trends Cogn Sci 15: 409-416.

21. Voineagu I (2011) Gene expression studies in autism: moving from the genome to the transcriptome and beyond. Neurobiol Dis 45: 69-75.

22. Miles JH (2011) Autism spectrum disorders--a genetics review. Genet Med 13: 278-294.

23. Chao HT, Chen H, Samaco RC, Xue M, Chahrour M, et al. (2010) Dysfunction in GABA signalling mediates autism-like stereotypies and Rett syndrome phenotypes. Nature 468: 263-269

24. Sakai Y, Shaw CA, Dawson BC, Dugas DV, Al-Mohtaseb, et al. (2011) Protein interactome reveals converging molecular pathways among autism disorders. Sci Transl Med 3: 86ra49.

25. Aldinger KA, Plummer JT, Qiu S, Levitt P (2011) SnapShot: genetics of autism. Neuron 72: 418-418e1.

26. Gilman SR, lossifov I, Levy D, Ronemus M, Wigler M, et al. (2011) Rare de novo variants associated with autism implicate a large functional network of genes involved in formation and function of synapses. Neuron 70: 898-907.

27. Levy D, Ronemus M, Yamrom B, Lee YH, Leotta A, et al. (2011) Rare de novo and transmitted copy-number variation in autistic spectrum disorders. Neuron 70: 886-897.

28. Sanders SJ, Ercan-Sencicek AG, Hus V, Luo R, Murtha MT, et al. (2011)
Multiple recurrent de novo CNVs, including duplications of the $7 q 11.23$ Williams syndrome region, are strongly associated with autism. Neuron 70: 863-885.

29. Casey JP, Magalhaes T, Conroy JM, Regan R, Shah N, et al. (2011) A novel approach of homozygous haplotype sharing identifies candidate genes in autism spectrum disorder. Hum Genet.

30. Konopka G, Wexler E, Rosen E, Mukamel Z, Osborn GE, et al. (2011) Modeling the functional genomics of autism using human neurons. Mol Psychiatry.

31. Lu AT, Yoon J, Geschwind DH, Cantor RM (2011) QTL replication and targeted association highlight the nerve growth factor gene for nonverbal communication deficits in autism spectrum disorders. Mol Psychiatry.

32. Hirschhorn JN, Gajdos ZK (2011) Genome-wide association studies: results from the first few years and potential implications for clinical medicine. Annu Rev Med 62: 11-24.

33. Crespi B, Stead P, Elliot M (2010) Evolution in health and medicine Sackler colloquium: Comparative genomics of autism and schizophrenia. Proc Nat Acad Sci U S A 1: 1736-1741.

34. Hu VW, Addington A, Hyman A (2011) Novel autism subtype-dependent genetic variants are revealed by quantitative trait and subphenotype association analyses of published GWAS data. PLoS One 6: e19067.

35. Holt R, Monaco AP (2011) Links between genetics and pathophysiology in the autism spectrum disorders. EMBO Mol Med 3: 438-450.

36. Burdick KE, Gopin CB, Malhotra AK (2011) Pharmacogenetic approaches to cognitive enhancement in schizophrenia. Harv Rev Psychiatry 19: 102-108.

37. Heilig M, Goldman D, Berrettini W, O’Brien CP (2011) Pharmacogenetic approaches to the treatment of alcohol addiction. Nat Rev Neurosci 12: 670684.

38. Burdick KE, Gopin CB, Malhotra AK (2011) Pharmacogenetic approaches to cognitive enhancement in schizophrenia. Harv Rev Psychiatry 19: 102-108.

39. Khokhar JY, Ferguson CS, Zhu AZ, Tyndale RF (2010) Pharmacogenetics of drug dependence: role of gene variations in susceptibility and treatment. Annu Rev Pharmacol Toxicol 50: 39-61.

40. Mroziewicz M, Tyndale RF (2011) Pharmacogenetics: a tool for identifying genetic factors in drug dependence and response to treatment. Addict Sci Clin Pract 5: 17-29.

41. Lohoff FW, Ferraro TN (2010) Pharmacogenetic considerations in the treatment of psychiatric disorders. Expert Opin Pharmacother 11: 423-439.

42. Bondy B (2005) Pharmacogenomics in depression and antidepressants Dialogues Clin Neurosci 7: 223-230.

43. Ho MK, Goldman D, Heinz A, Kaprio J, Kreek MJ, et al. (2010) Breaking barriers in the genomics and pharmacogenetics of drug addiction. Clin Pharmacol Ther 88: 779-791.

44. Demb H, Valicenti-McDermott M, Navarro A, Ayoob KT (2011) The effect of long-term use of risperidone on body weight of children with an autism spectrum disorder. J Clin Psychopharmacol 31: 669-670.

45. Lemmon ME, Gregas M, Jeste SS (2011) Risperidone use in autism spectrum disorders: a retrospective review of a clinic-referred patient population. J Child Neurol 26: 428-432.

46. Tobiasova Z, van der Lingen $\mathrm{KH}$, Scahill L, Leckman JF, Zhang $\mathrm{Y}$, et al (2011) Risperidone-Related Improvement of Irritability in Children with Autism Is not Associated with Changes in Serum of Epidermal Growth Factor and Interleukin-13. J Child Adolesc Psychopharmacol 21: 555-564.

47. Valdovinos MG, Bailey L, Taylor SL (2010) Examining risperidone use in those diagnosed with autism 1 year after FDA approval. J Clin Psychiatry 71: 651652.

48. Aman MG, Hollway JA, McDougle CJ, Scahill L, Tierney E, et al. (2008) Cognitive effects of risperidone in children with autism and irritable behavior. $J$ Child Adolesc Psychopharmacol 18: 227-236.

49. Canitano R, Scandurra V (2008) Risperidone in the treatment of behaviora disorders associated with autism in children and adolescents. Neuropsychiat Dis Treat 4: 723-730. 
Citation: Wang H (2012) Pharmacogenomics: A Promising Approach Towards Treatment of Autism. J Pharmacogenom Pharmacoproteomics 3:e110. doi:10.4172/2153-0645.1000e110

Page 4 of 4

50. Correia CT, Almeida JP, Santos PE, Sequeira AF, Marques CE, et al. (2010) Pharmacogenetics of risperidone therapy in autism: association analysis of eight candidate genes with drug efficacy and adverse drug reactions. Pharmacogenomics J 10: 418-430.

51. Montgomery S, Hansen T, Kasper S (2011) Efficacy of escitalopram compared to citalopram: a meta-analysis. Int J Neuropsychopharmacol 14: 261-268.

52. Muhonen LH, Lahti J, Alho H, Lonnqvist J, Haukka J, et al. (2011) Serotonin transporter polymorphism as a predictor for escitalopram treatment of major depressive disorder comorbid with alcohol dependence. Psychiatry Res 186: 53-57.

53. Ou JJ, Xun GL, Wu RR, Li LH, Fang MS, et al. (2011) Efficacy and safety of escitalopram versus citalopram in major depressive disorder: a 6-week, multicenter, randomized, double-blind, flexible-dose study. Psychopharmacology (Berl) 213: 639-646.

54. Hu XZ, Lipsky RH, Zhu G, Akhtar LA, Taubman J, et al. (2006) Serotonin transporter promoter gain-of-function genotypes are linked to obsessivecompulsive disorder. Am J Hum Genet 78: 815-826.
55. Owley T, Brune CW, Salt J, Walton L, Guter S, et al (2010) A pharmacogenetic study of escitalopram in autism spectrum disorders. Autism Res 3: 1-7.

56. Lit L, Sharp FR, Bertoglio K, Stamova B, Ander BP, et al. (2011) Gene expression in blood is associated with risperidone response in children with autism spectrum disorders. Pharmacogenomics $\mathrm{J}$.

57. Shen Y, Dies KA, Holm IA, Bridgemohan C, Sobeih MM, et al. (2010) Clinical genetic testing for patients with autism spectrum disorders. Pediatrics 125: e727-735.

58. Vassos E, Collier DA, Holden S, Patch C, Rujescu D, et al. (2010) Penetrance for copy number variants associated with schizophrenia. Hum Mol Genet 19 : 3477-3481.

59. Magiati I, Moss J, Yates R, Charman T, Howlin P (2011) Is the Autism Treatment Evaluation Checklist a useful tool for monitoring progress in children with autism spectrum disorders? J Intellect Disabil Res 55: 302-312. 